\title{
BEHAVIOR OF PARTIAL STRENGTH OF BEAM-TO- COLUMN CONNECTION WITH GUSSET PLATE FOR COLD-FORMED STEEL SECTIONS
}

\author{
Muhammad Firdaus ${ }^{1}$, Anis Saggaff ${ }^{2}$, Mahmood Md Tahir ${ }^{3 *}$, Kiagus Muhammad \\ Aminuddin², Shek Poi Ngian³, Tan Cher Siang', Musab Nimir Ali Salih³, Hossein \\ Mohammadhosseini $^{3}$, and Arizu Sulaiman ${ }^{3}$ \\ ${ }^{1}$ Civil Engineering Department, Faculty of Engineering, PGRI University Palembang, Indonesia, e-mail: \\ firdaus@univpgri-palembang.ac.id \\ ${ }^{2}$ Civil Engineering Department, Faculty of Engineering, Universitas Sriwijaya, Inderalaya, Indonesia, e-mail: \\ anissaggaf@unsri.ac.id \\ ${ }^{3}$ Institute for Smart Infrastructure and Innovative Construction, UTM Construction Research Centre, School of Civil \\ Engineering,Faculty of Engineering, Universiti Teknologi Malaysia, Johor Bahru, Malaysia, e-mail: \\ *mahmoodtahir@utm.my,mhossein@utm.my, aminuddin.km73@gmail.com, shekpoingian@utm.my, \\ tcsiang@utm.my, nasmusab2@live.utm.my, arizu@utm.my
}

Received Date: October 18, 2019; Revised Date: April 17, 2020; Acceptance Date: August 11, 2020

\begin{abstract}
The use of cold-formed steel (CFS) as part of a major construction has been rapidly increasing recently, as it is considered viable as an alternative to the conventional hot-rolled steel section. However, information about CFS as part of a non-composite system is still limited as the connection is designed as a pinned connection, only good for roof trusses and wall paneling. The aim of this research is to propose a connection for CFS sections that could enhance the strength of typical CFS connections, from pinned to partial strength connections. This paper presents the behavior of the partial strength of a non-composite beam-to-column connection for a cold-formed steel section where a gusset plate was used as a stiffener. This type of proposed connection for CFS is not limited only to the construction of roof trusses and wall cladding, but is also able to provide better flexural strength in semi-continuous construction. The proposed connections consisted of 6 specimens divided into two types, the first of which were stiffened by the gusset plate and the second of which were enhanced further with the top, seat and web angles. From the results of the experimental tests it was concluded that all the proposed connections can be categorized as partial strength connections, where the strength was more than $25 \%$ of the connected beam and suitable for use in semicontinuous construction. A relatively good agreement was recorded for the comparison between the experimental results and the predicted results from the EC3 component method super-imposed with a haunched gusset plate and top, seat and web angle components, which differed in the range of 1.31 to 1.5 times for the moment resistance and 1.07 to 1.37 times for the stiffness of the proposed connections.
\end{abstract}

Keywords: Cold-formed steel, Gusset plate, Moment-rotation, Top-seat and web angle

\section{Introduction}

In general, steel manufacturing processes are divided into two methods: hot-rolled steel (HRS) which is rolled at high temperatures and cold-formed steel (CFS) which is rolled at relatively low temperatures. CFS sections are made up of steel coils produced by cold-rolling or press braking, 
and this material is often referred to as a lightweight material because its thickness is less than 3 $\mathrm{mm}$ [1]. It is undeniable that CFS is superior in terms of its weight to strength ratio compared to HRS. CFS is easier to use in the construction process because it can be cut and erected with a minimum workforce. Besides that, the construction tools are easier to operate even with one person, and it is environmentally friendly and pest-resistant. These advantages of CFS mean that it can be promoted as an alternative to traditional construction materials such as hot-rolled steel, wood, and stone [2].

However, there is also a weakness of CFS, due to its thin plate behavior, where at high stress concentrations the plate tends to develop premature buckling or local deformation. In this paper, therefore, research work on CFS was carried out as the information on the structural performance as a partial strength connection with moment resistance was found to be very limited. The design recommendations for CFS have been largely focused on the individual components' connection capacity (e.g. bolts, tapping screws), and do not cover the aspect of components such as the gusset plate and top, seat and web cleat angle in the connection [3]. Several investigations have recently been conducted on CFS non-composite connections, taking into consideration the contribution of other connection components. Bucmys reported that one type of connection that is fast and easy to install is the gusset plate [4]. Dubina, Stratan et al. [5] evaluated the performance of a CFS double-pitched roof channel back-to-back with a gusset-plate bolt connection, and implemented the component method to determine the characteristics of the connection. The results showed that the use of the gusset plate in the CFS connection significantly increases the moment resistance of the connection, which can be classified as a partial strength connection. Ali, Saad et al. [6] carried out laboratory tests on a simple connection with a single lipped-channel back-toback profile bolted back-to-back on the joint. A large deformation developed on the beam in the test such that the tested connections failed due to bearing failure on the beam.

Efforts were made to increase the lightweight section ductility by stiffening flange parts from flat to curves, combined with an out-of-plane stiffener placed on the beam web [7, 8]. The connections are a significant part of the structure and act to distribute the load to each member of the structure. The performance of the connection is highly dependent on strength, stiffness, and ductility. Practitioners mostly assume that the connection is a pin or rigid. This method is often applied because of practical considerations, or due to some gap of knowledge. The consequence is an overestimation of the section dimensions, or complicated connections, especially for rigid joints. This will influence the associated cost, which can reach up to $50 \%$ of the total building cost [9]. Furthermore, some of the previous studies have proven that the ideal concept (pin or rigid) does not describe the actual non-linear behavior of the connection. A more appropriate concept is semi-rigid (based on rigidity) or partial strength (based on strength), where the behavior is between these ideal conditions (pinned and rigid connections). The semi-rigid connections which are usually associated with partial strength have several advantages, including reducing the depth and weight of the beam. In addition, the partial strength concept allows for ductile rotation but stiffer connection as compared with pinned connection [10]. The typical CFS is designed as a pinned connection as the section is very thin (Class 4 or slender section), which usually fails due to premature deformation and buckling. A pinned connection is defined as a connection with a moment resistance limited to up to $25 \%$ of the connection part only. Therefore, in order to enhance 
the connection, a haunched gusset plate is proposed, whereby the moment resistance of the connection is enhanced by the use of the top, seat and web angles. Bagheri Sabbagh et al. [11] stated that the joint performance is also influenced by the flexural strength of the beam and the slip of bolt against the bolt hole, especially for cyclic loads. Ye, Mojtabaei et al. [12] proved that the combination of the gusset plate in CFS beams was reliable for earthquake-resistant portal systems. As shown in Figure 1, the top and seat angle connection is able to develop a more robust joint than the header plate and web angle [13]. Therefore, the use of the top, seat and web angles together with a gusset plate can further increase the moment resistance of the connection for CFS, such that welding work can be avoided [14]. However, more in-depth efforts are needed to understand the behavior of the proposed connection with the haunched gusset plate. Therefore, this paper presents research on the use of CFS with a haunched gusset plate, combined with the top, seat, and web angles as added connections, as research on these components is not yet well established.

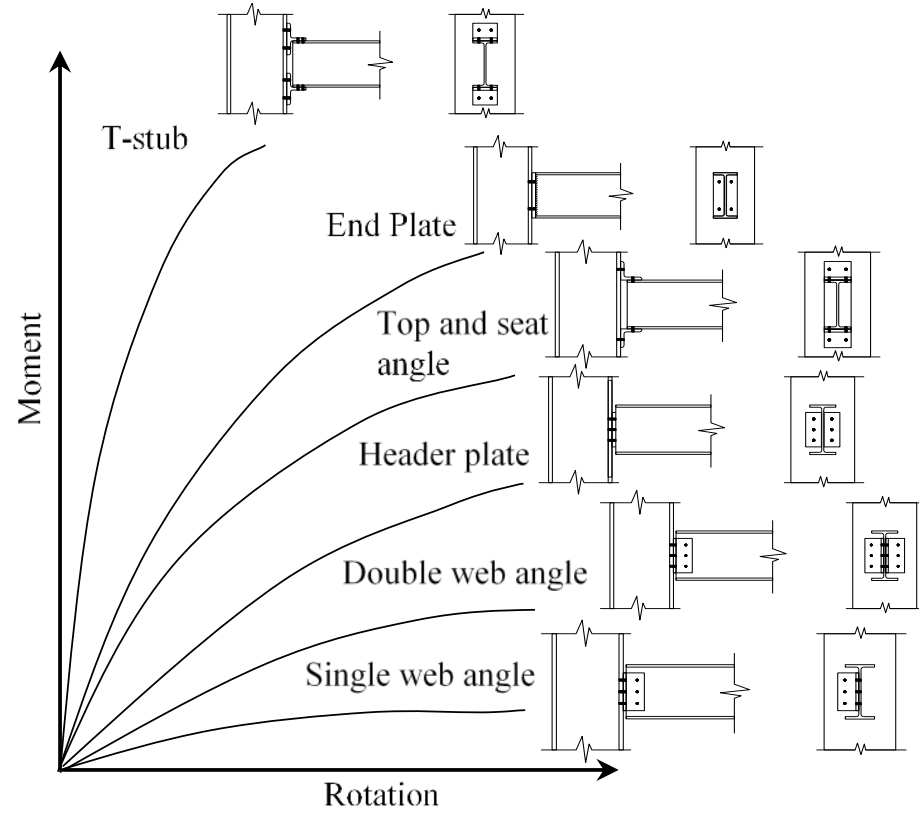

Figure 1. Moment-rotation curve zof semi-rigid joints [13]

Previous research has proven that top, seat and web angle connections have good performance and can be used to replace reinforcement without the need to dismantle existing constructions $[15,16]$. Faella [17] presented numerical analysis procedures regarding the design of the top, seat, and web angle joints of an HRS section and were able to predict the moment resistance and the stiffness of the joint. Faella compared the full-scale test results with the numerical analysis and found the results to agree well. Pisarek [18] proposed a more concise method to design the connection using the top, seat and web angle, with the formula entirely referring to EC3. However, both of these investigations focused only on HRS profiles.

The literature review identified a lack of research on the haunched gusset plate, combined with the top, seat, and web angles. In this paper, the behavior of a non-composite connection was examined. The proposed connections comprised 6 specimens divided into two types, the first stiffened by a gusset plate and the second enhanced further with the top, seat and web angles. The 
objectives are then to predict the moment resistance and stiffness of the proposed connection by developing new formulation procedures based on the component method for cold-formed steel connections and, moreover, to develop the moment-rotation curve of the proposed connection by conducting full-scale testing of the beam-to-column connection. The scope of the study is to present experimental test results for the proposed connection and compare these with the numerical analysis.

\section{Parameters of the Specimens}

Two types of proposed connections are tested for full-scale testing in this paper: the haunched gusset plate (Figure 2) and the gusset plate combination with the top, seat and web angles (Figure 3). The CFS beam-to-column connections consisted of a hot-rolled gusset plate of $10 \mathrm{~mm}$ thickness and connected to the beam and column by means of M12 bolts. The full-scale testing of six specimens was prepared and tested until failure.

For the first type (Figure 2), the specimens were coded as BGJ-07, BGJ-08 and BGJ-09, respectively. Details of the parameters and material used are tabulated in Table 1 . The beam comprising a Double Lipped C-Channel (DLC) section was arranged back-to-back and connected with M12 bolts (Figure 4 and Table 2). The resistance of the DLC in bending ( $\left.\mathbf{M}_{\mathrm{cx}}\right)$ was calculated from the formula proposed by Dubina [1]. The CFS steel grade was prepared for the coupon tests based on procedures regulated in BS EN10002-1 [19], where the average results were fy $=597$ $\mathrm{MPa}$ for yield strength and $\mathrm{fu}=683 \mathrm{MPa}$ for ultimate strength. The diameter of the bolt holes was $13 \mathrm{~mm}$ as specified in EN 1090-2 for M12 bolts [20]. The same bolts were also used by Lawan [21] and tested for tension tests, recording fy $=758 \mathrm{MPa}$ and fu $=834 \mathrm{MPa}$. For the second type of connection (Figure 3), the test specimens were labelled as IJT-07, IJT-08 and IJT-09, and a haunched gusset plate of $10 \mathrm{~mm}$ thickness was assembled together with top and bottom angle cleats of size $100 \times 75 \times 7 \mathrm{~mm}$. The top angle was positioned at the top of the beam flange, which contributed to increasing the tension zone. The bottom angle cleat was also installed to avoid premature buckling failure due to the compression force. The connection was further enhanced by installing a web angle which connected the web of the beam to the column flange.
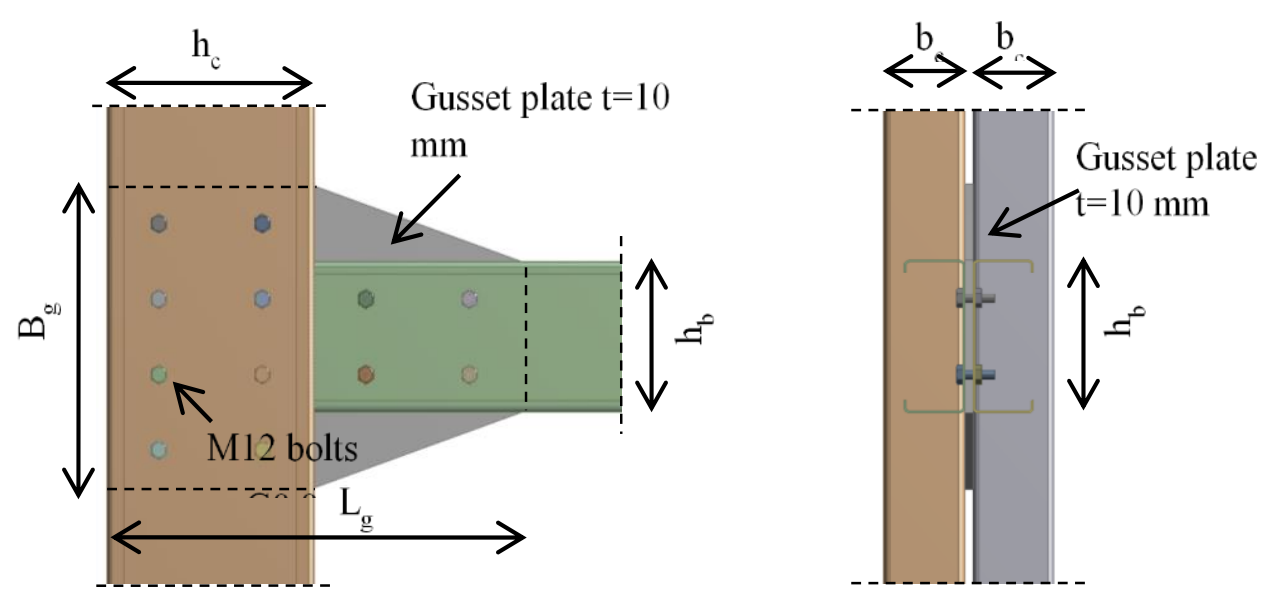

Figure 2. Haunched gusset plate connection for BGJ specimen 
Table 1. Material Size and Strength

\begin{tabular}{|c|c|c|c|c|c|c|c|}
\hline Type & $\begin{array}{l}\text { Test } \\
\text { ID }\end{array}$ & Beam & Column & $\begin{array}{c}\text { Gusset } \\
\text { Plate } \\
\text { Thickness } \\
\text { (mm) }\end{array}$ & $\begin{array}{c}\text { Web } \\
\text { Angle }\end{array}$ & $\begin{array}{c}\text { Seat } \\
\text { Angle }\end{array}$ & Bolt \\
\hline \multirow[t]{3}{*}{1} & BGJ-07 & DLC200 & DLC300 & 10 & - & - & M12 \\
\hline & BGJ-08 & DLC250 & DLC300 & 10 & - & - & M12 \\
\hline & BGJ-09 & DLC300 & DLC300 & 10 & - & - & M12 \\
\hline \multirow[t]{8}{*}{2} & IJT-07 & DLC200 & DLC300 & 10 & L100x $75 \times 7$ & L100x75x 7 & M12 \\
\hline & IJT-08 & DLC250 & DLC300 & 10 & L100x $75 \times 7$ & L100x75x 7 & M12 \\
\hline & IJT-09 & DLC300 & DLC300 & 10 & L100x $75 \times 7$ & L100x $75 \times 7$ & M12 \\
\hline & fy(MPa) & 545 & 545 & 321 & 350 & 350 & 758 \\
\hline & fu(MPa) & 637 & 637 & 465 & 505 & 505 & 834 \\
\hline & Notes & $\begin{array}{c}\text { Coupon } \\
\text { test }\end{array}$ & $\begin{array}{l}\text { Coupon } \\
\text { test }\end{array}$ & $\begin{array}{l}\text { Coupon } \\
\text { test }\end{array}$ & S350 & S350 & $\begin{array}{l}\text { Lawan } \\
\text { (2015) }\end{array}$ \\
\hline & $\infty^{\infty n}$ & $\begin{array}{ll}- & 0 . \\
0 & 0 .\end{array}$ & & $\begin{array}{l}\text { set plate } \\
10 \mathrm{~mm}\end{array}$ & & $\begin{array}{l}\text { op angle } \\
00 \times 75 \times 7\end{array}$ & \\
\hline & 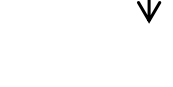 & & $\stackrel{\mathrm{L}_{\mathrm{g}}}{\longrightarrow} \quad 100 \mathrm{x}$ & & & $\begin{array}{l}\text { Seat angle } \\
100 \times 75 \times 7\end{array}$ & \\
\hline
\end{tabular}

Figure 3. Gusset plate connection with top, seat and web angles for IJT specimen

Stress concentrations usually develop at concave corners if the "T-shape" is selected, so the haunched gusset plate shape was instead chosen so that the stress concentration could be reduced as shown in Figure 5. In addition, this shape can directly increase the stiffness and strength of the joint. The positions of the bolts on the gusset plate were arranged according to the requirements suggested in EC3 (Table 3). The steel grade of the gusset plates was also used based on the coupon test, with fy $=321 \mathrm{MPa}$ and $\mathrm{fu}=465 \mathrm{MPa}$.

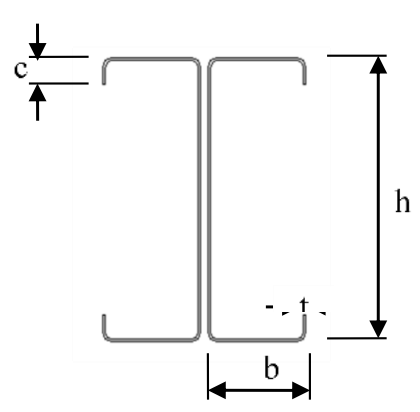

Figure 4.Double-lipped channel

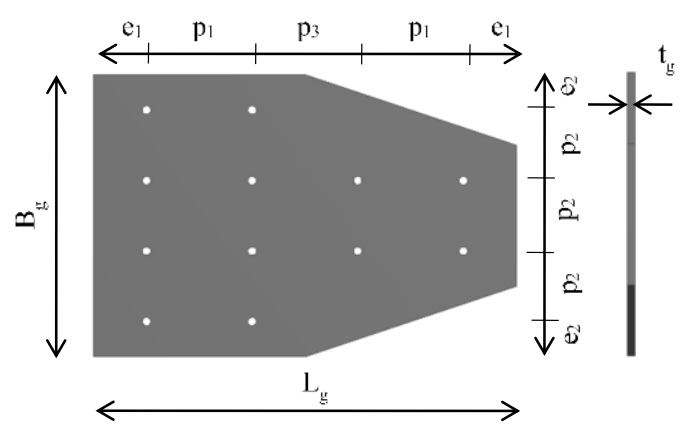

Figure 5. Gusset plate profile 
Table 2. Dimensions of Double-Lipped Channel

\begin{tabular}{cccccc}
\hline Dimension & $\begin{array}{c}\mathbf{h} \\
\mathbf{m m}\end{array}$ & $\begin{array}{c}\mathbf{b} \\
\mathbf{m m}\end{array}$ & $\begin{array}{c}\mathbf{c} \\
\mathbf{m m}\end{array}$ & $\begin{array}{c}\mathbf{t} \\
\mathbf{m m}\end{array}$ & $\begin{array}{c}\mathbf{M}_{\mathbf{c x}} \\
\mathbf{k N m}\end{array}$ \\
\hline DLC200 & 200 & 75 & 16 & 2.4 & 48.297 \\
DLC250 & 250 & 75 & 20 & 2.4 & 63.713 \\
DLC300 & 300 & 100 & 25 & 2.4 & 79.684 \\
\hline
\end{tabular}

Table 3. Bolt Distance

\begin{tabular}{cccccccc}
\hline $\begin{array}{c}\text { Test } \\
\text { ID }\end{array}$ & $\begin{array}{c}\text { Bg } \\
\mathbf{m m}\end{array}$ & $\begin{array}{c}\mathbf{L g} \\
\mathbf{m m}\end{array}$ & $\begin{array}{c}\mathbf{e 1} \\
\mathbf{m m}\end{array}$ & $\begin{array}{c}\mathbf{e 2} \\
\mathbf{m m}\end{array}$ & $\begin{array}{c}\mathbf{p 1} \\
\mathbf{m m}\end{array}$ & $\begin{array}{c}\mathbf{p 2} \\
\mathbf{m m}\end{array}$ & $\begin{array}{c}\mathbf{p 3} \\
\mathbf{m m}\end{array}$ \\
\hline BGJ-07 & 400 & 600 & 75 & 50 & 150 & 100 & 150 \\
BGJ-08 & 550 & 600 & 75 & 50 & 150 & 100 & 150 \\
BGJ-09 & 600 & 600 & 75 & 75 & 150 & 150 & 150 \\
IJT-07 & 400 & 600 & 75 & 50 & 150 & 100 & 150 \\
IJT-08 & 550 & 600 & 75 & 50 & 150 & 100 & 150 \\
IJT-09 & 600 & 600 & 75 & 75 & 150 & 150 & 150 \\
\hline
\end{tabular}

\section{Test Set-Up and Procedures}

The tested specimens were assembled in such a way that the column and beam were connected to the proposed connection as shown in Figure 6. The cantilever beam length was $1000 \mathrm{~mm}$ and can be considered sufficient to represent the contra-flexure position of the beam. The column is restrained at each end with the purpose of keeping the specimen in its position; a 3 meter height was chosen to represent the height of a column of part of the portal (sub-frame) of a multi-story building. The test variables used were the size of the beam, the size of the gusset plate, and the effect of the top, seat and web angles on the connection. The isolated joint test procedure was carried out by applying a point load placed at the end of the cantilever beam, and the distance was 1 meter from the face of the column. The load was increased gradually until the failure mode was reached, when the load applied dropped gradually. Two inclinometers were installed at the beam (I-1) and column (I-2) positions to measure the rotation of the connection (Figure 6(a)). In order to avoid the occurrence of torsional deformation at the beam end, lateral bracing was used, placed at the right and left side of the beam (Figure 6(b)).

The rotation of the connection is defined as the difference between the rotation of the column and the rotation of the beam. The inclinometer I-1 was placed $100 \mathrm{~mm}$ from the column flange, where the beam flexural effect does not influence the rotation of the joint. The incremental loading was given within a range of 0.2 to $0.5 \mathrm{kN}$ using a manual hydraulic jack. The unloading procedure was conducted after one-third of the predicted load was reached. This procedure was conducted in order to allow the specimen to be set up in an equilibrium. The experiment then continued until failure of the specimen was observed. 
(a) Instumententation setting up 1000

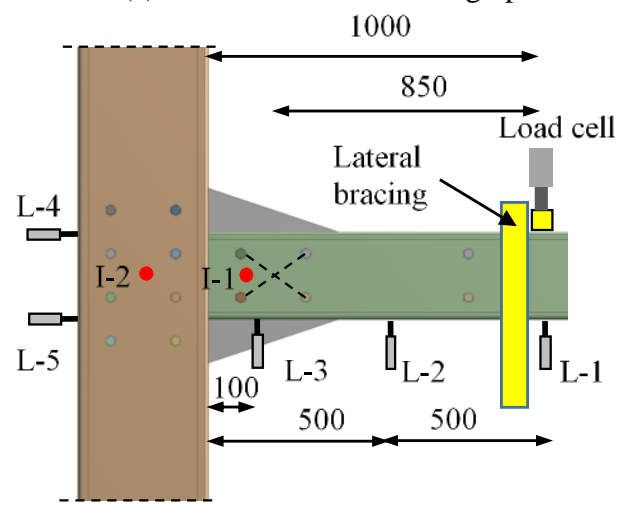

(b) Experimental setting up

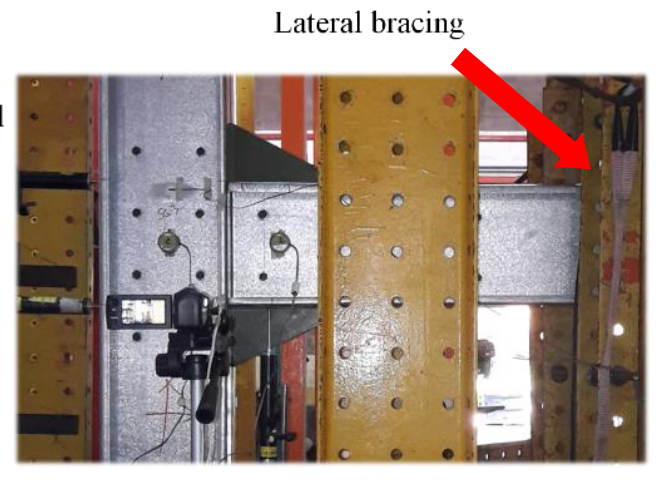

Figure 6. Instruments used in isolated joint test for tested specimens

\section{Numerical Analysis}

EC3 offers a component method to predict the moment resistance of the proposed connection. In principle, the component method categorizes failure based on the failure of the connection component at the beam and column. In this paper, the basic joint component design resistance and stiffness coefficient, referring to Table 6.1 of EC3 [22], involve components including web columns, column flanges, flange cleats, bolts in tension, bolts in bearing, bolts in shear, beam flanges and beam webs. However, no formulation or guidelines are given for the gusset plate and top seat as connection components. Therefore, the calculation procedure for a haunched gusset plate as presented in this paper was adopted based on EC3 by superimposing the contribution of the proposed component on the other connection components. The moment resistance of the connection can be expressed by the superposition of the gusset plate $\left(\mathrm{M}_{\mathrm{j}, \mathrm{gp}, \mathrm{Rd}}\right)$ and top, seat, and web angles $\left(\mathrm{M}_{\mathrm{j}, \mathrm{tsw}, \mathrm{Rd}}\right)$ with the equation:

$$
\begin{gathered}
M_{j, g p, R d}=\min \left(M_{j, b b g}, M_{j, c b g}, M_{j, g b g}\right) ; M_{j, t s w, R d}=\Sigma F_{i, R d} \cdot h_{i} \\
M_{j, R d}=M_{j, g p, R d}+M_{j, t s w, R d}
\end{gathered}
$$

where: $\mathrm{M}_{\mathrm{j}, \mathrm{bbg}}$ is the moment resistance of the beam bolt group; $\mathrm{M}_{\mathrm{j}, \mathrm{cbg}}$ is the moment resistance of the column bolt group; $\mathrm{M}_{\mathrm{j}, \mathrm{gbg}}$ is the moment resistance of the gusset plate bolt group; $\mathrm{F}_{\mathrm{i}, \mathrm{Rd}}$ is the bolt-row resistance and $h_{i}$ is the lever arm for each bolt-row.

To predict the exact stiffness of the connection is quite difficult. By assuming that the total rotation of the connection is equal to the rotation on the gusset plate and the top, seat, and web angles, the joint stiffness can be written as the sum of the stiffness of the gusset plate $\left(\mathrm{S}_{\mathrm{j}, \mathrm{gp}}\right)$ and the top, seat and web angles $\left(\mathrm{S}_{\mathrm{j}, \text { tsw }}\right)$ as shown in Equation (3). The stiffness of $\mathrm{S}_{\mathrm{j}, \text { tsw was }}$ calculated in accordance with EC3 procedures and the same procedures were also adopted by Faella [17] and Pisarek [18]. Bucmys [4] introduced the equation of the stiffness of the gusset plate joint $\left(\mathrm{S}_{\mathrm{j}, \mathrm{gp}}\right)$ as the sum of the series of the stiffness of the beam bolt group $\left(\mathrm{S}_{\mathrm{b}, \mathrm{bg}}\right.$, ini), column bolt group $\left(\mathrm{S}_{\mathrm{c}, \mathrm{bg}, \text { ini }}\right)$ and the gusset plate itself $\left(\mathrm{S}_{\mathrm{gp}, \text { ini }}\right)$ using Equation (4). 


$$
\begin{gathered}
\mathrm{S}_{j}=\mathrm{S}_{j, g p}+\mathrm{S}_{j, t s w} \\
S_{j, g p}=\frac{1}{\frac{1}{S_{b, b g, i n i}}+\frac{1}{S_{c, b g, i n i}}+\frac{1}{S_{g p, i n i}}}
\end{gathered}
$$

Due to the absence of instructions to analyze the gusset plate in EC3, Bucmys proposed Equation (6) to obtain the gusset plate stiffness, where the total rotation is a superposition of rotation $(\phi 1)$ due to shear force $(\mathrm{P})$, rotation $(\phi 2)$ and rotation $(\phi 3)$ due to bending moments at the beam and column respectively (see Figure 7). Equation (6) of the gusset plate stiffness ( $\left.S_{\mathrm{gp}, \text { ini }}\right)$ is described below:

$$
S_{g p, i n i}=\frac{\mathrm{M}_{\mathrm{c}}}{\phi_{1}+\phi_{2}+\phi_{3}} ; M_{c}=P . L_{2} ; M_{b}=P . L_{1}
$$
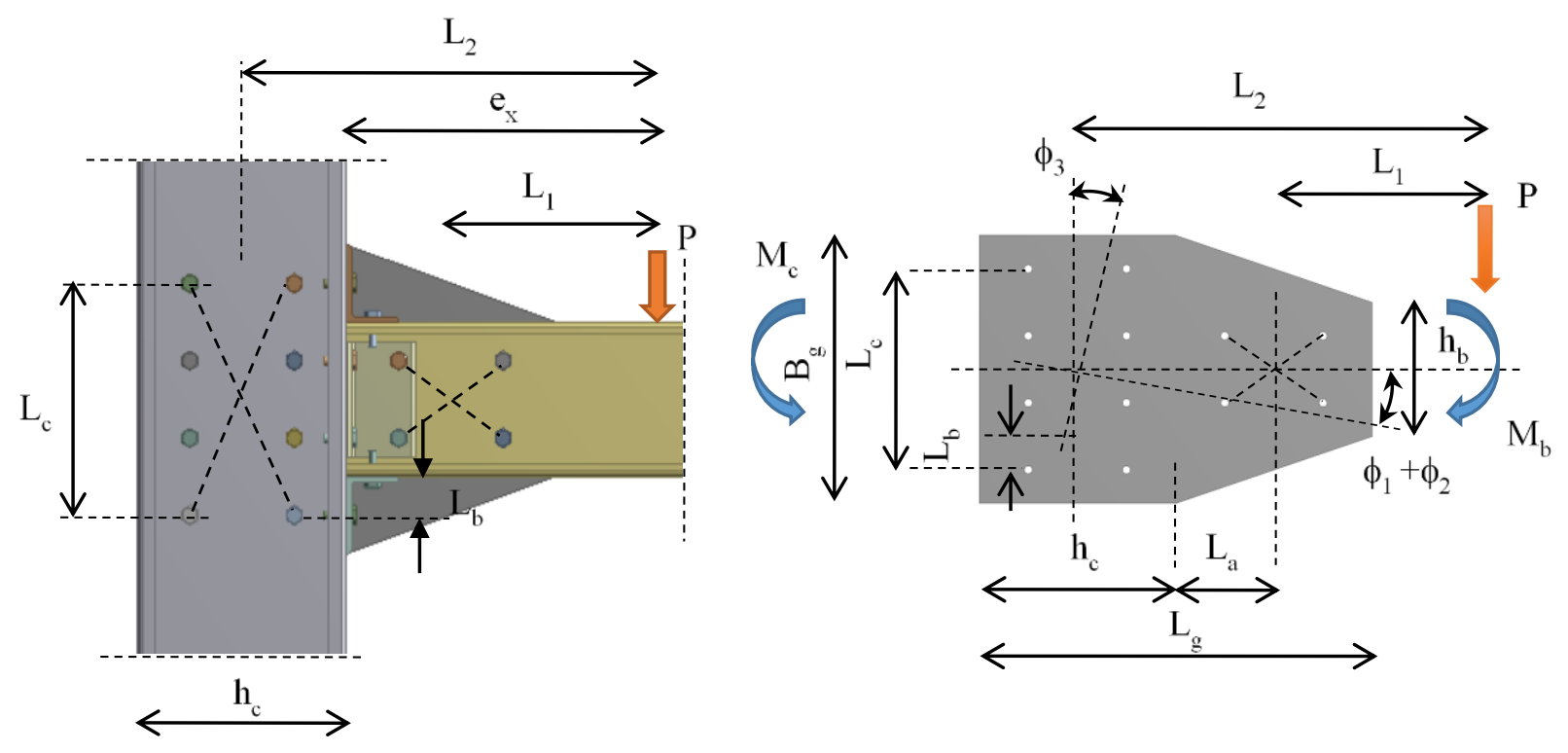

Figure 7. Gusset plate rotational scheme

However, Equation (6) is only applicable for rectangular and T-shaped gusset plates. Therefore, with reference to Figure 7 , the rotational factor for the haunched gusset plate is introduced. The rotation of the outstanding elements is approached by means of tapered beam theory, as described below. The integral factor $\mathrm{K}$ is proposed as the portion of the plate connected to the beam and column with a ratio of width $r_{b}=B_{g} / h_{b}$ and $r_{c}=L_{g} / h_{c}$.

$$
\phi_{1}=\frac{P \cdot L_{a}^{2}}{E_{S} \cdot I_{b}} \cdot K_{3, b}^{1} ; \phi_{2}=\frac{M_{b} \cdot L_{a}}{E_{S} \cdot I_{b}} \cdot K_{3, b}^{0} ; \phi_{3}=\frac{M_{c} \cdot L_{b}^{2}}{L_{c} \cdot E_{s} \cdot I_{c}} \cdot K_{3, c}^{1}
$$




$$
\begin{gathered}
K_{3, b}^{0}=\int_{0}^{1} \frac{\xi^{0}}{\left(1+\left(r_{b}-1\right) \xi\right)^{3}} d \xi ; K_{3, b}^{1}=\int_{0}^{1} \frac{\xi^{1}}{\left(1+\left(r_{b}-1\right) \xi\right)^{3}} d \xi ; \\
K_{3, c}^{1}=\int_{0}^{1} \frac{\xi^{1}}{\left(1+\left(r_{c}-1\right) \xi\right)^{3}} d \xi
\end{gathered}
$$

where: $\mathrm{E}_{\mathrm{s}}$ is the elastic modulus of steel; $\mathrm{I}_{\mathrm{b}}$ is the moment inertia of the beam and $\mathrm{I}_{\mathrm{c}}$ is the moment inertia of the column.

\section{Moment-Rotation Prediction}

Prediction of the moment-rotation was calculated by referring to EC3. The non-linear behavior was simplified in the form of a bi-linear curve. Figure 8 shows an example of the moment-rotation curve prediction, including the classification of joints in three ways, namely: (a) Strength; full strength if $\mathrm{M}_{\mathrm{j}}>\mathrm{M}_{\mathrm{cx}}$ and partial strength if $0.25 \mathrm{M}_{\mathrm{cx}}<\mathrm{M}_{\mathrm{j}}<\mathrm{M}_{\mathrm{cx}}$; (b) Stiffness; pinned if $\mathrm{S}_{\mathrm{j}}<\mathrm{S}_{\mathrm{j}}$ pinned, rigid if $S_{j}>S_{j}$, rigid, semi-rigid if $S_{j}$ pinned $<S_{j}<S_{j}$, rigid; (c) Ductility; classified as ductile if $\phi_{j}$ $>0.03$, not ductile if $\phi_{\mathrm{j}}<0.03$.

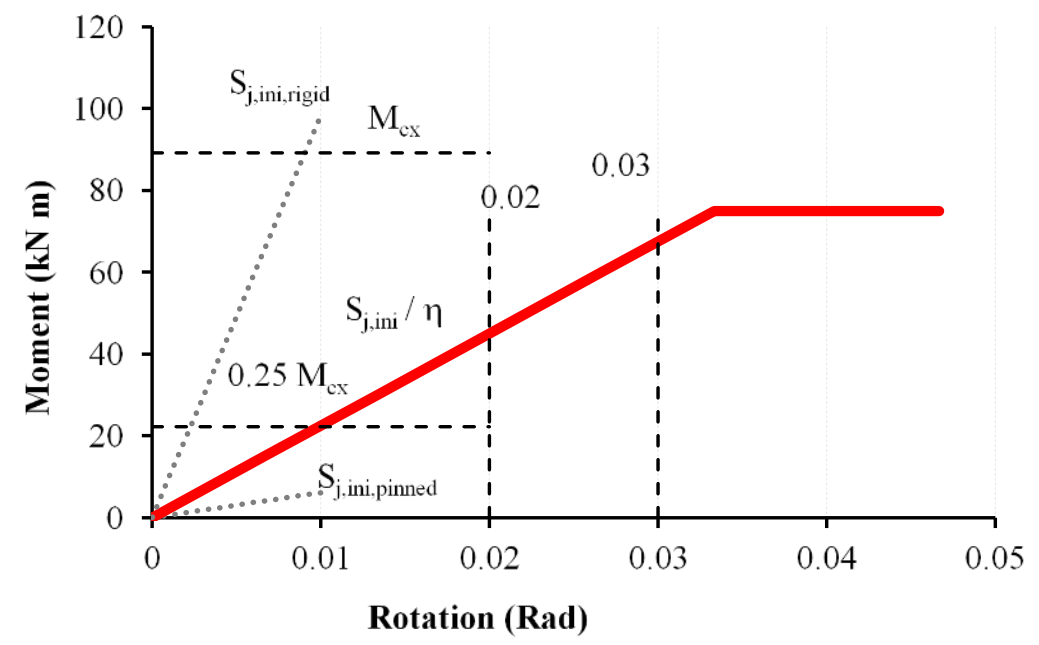

Figure 8. Moment-rotation in EC3

The classification boundaries for rigidity were derived from EC3 and can only be determined from a sub-assemblage frame test, because the span of the beam from the center to center of the columns $\left(\mathrm{Lb}_{b}\right)$ must be included as the equation below:

$$
\begin{gathered}
S_{j, \text { pinned }}=0.5 \frac{E_{S} I_{b}}{L_{b}} \\
S_{j, \text { rigid }}=k_{b} \frac{E_{S} I_{b}}{L_{b}}
\end{gathered}
$$

where $\mathrm{k}_{\mathrm{b}}$ is taken as: a. 8 for a bracing system; b. 25 for other frames. 


\section{Result and Discussion}

\section{Load-Deflection}

The monotonic loading was recorded by the data logger and presented in the form of a loaddeflection graph. To facilitate the study, the deformation of the specimens is shown only from LVDT-1 with a reading limited up to $100 \mathrm{~mm}$. In general, in the load-deflection graph from the experimental results (Figure 9) the overall behavior of the connection was ductile.

The maximum deflection of the six samples did not exceed the maximum LVDT limit of $100 \mathrm{~mm}$. This could be due to the high stiffness of the connection contributed by the haunched gusset plate and top seat. The maximum load was achieved for specimen BGJ-09 $(46.3 \mathrm{kN}, 83.7 \mathrm{~mm})$, followed by specimen BGJ-08 $(41.65 \mathrm{kN}, 83.33 \mathrm{~mm})$ and specimen BGJ07 (35.5 kN, $72.89 \mathrm{~mm})$, as shown in Figure 9(a).

The final load of the IJT specimens is higher than for the BGJ, which could be due to the influence of the use of the top, seat and web angles in the IJT specimens. Figure 9(b) displays the load-deflection graphs for specimens IJT-09 $(50 \mathrm{kN}, 58.13 \mathrm{~mm})$, IJT-08 (45 kN, $68.23 \mathrm{~mm})$ and IJT-07 $(37 \mathrm{kN}, 70.47 \mathrm{~mm})$ respectively.

a. BGJ specimen

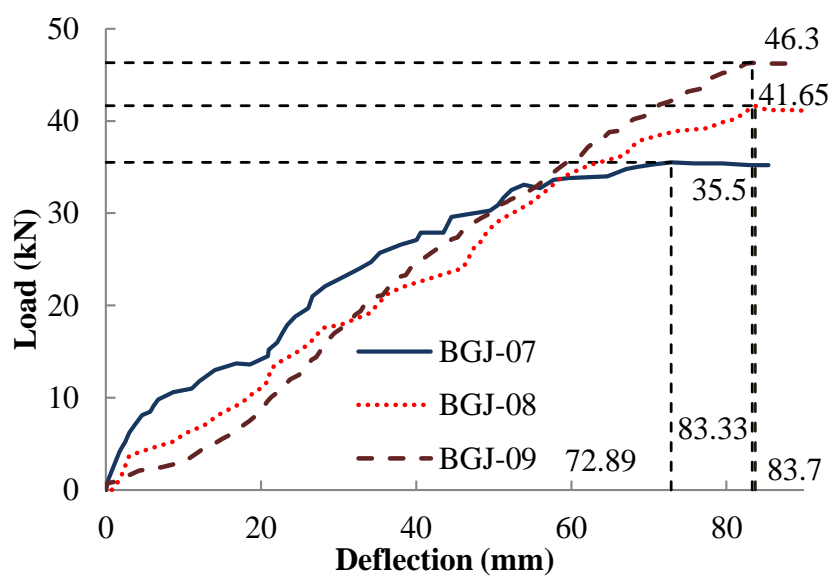

\section{b. IJT specimen}

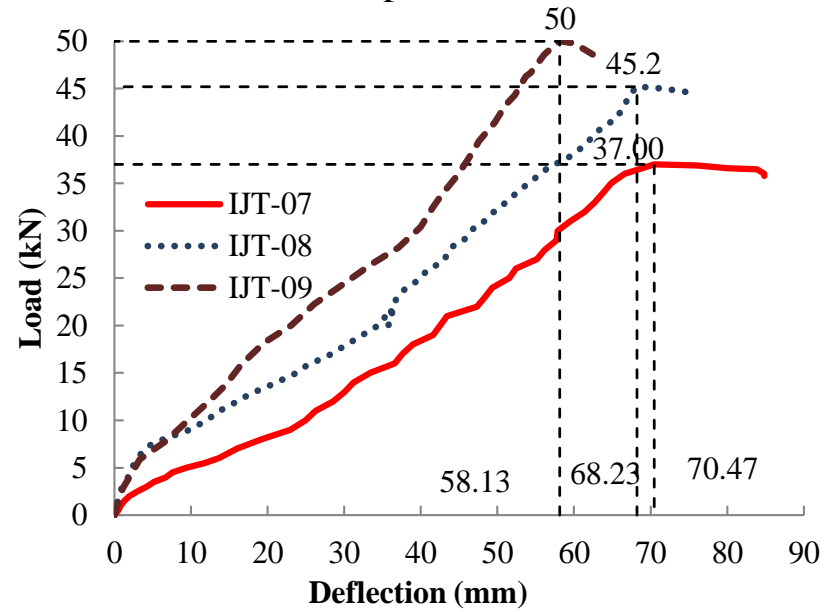

Figure 9. Typical load-deflection graphs for BGJ and IJT

The deformation of the BGJ specimens is presented in Figure 10. For the initial loads, the center of rotation is at the center of the beam bolt group. At the final stages, the rotation increases and causes the lower beam flange to 'push' the column flange located at the compression zone (marked with a red dashed circle). No damage was detected at the M12 bolts, so the excessive rotation at the beam could be due to bearing failure at the bolt holes. There was no visible bending at the column flange. However, the presence of local buckling observed at the column flanges indicates that the joint capacity was limited by resistance in the compression zone. 
a. BGJ-07

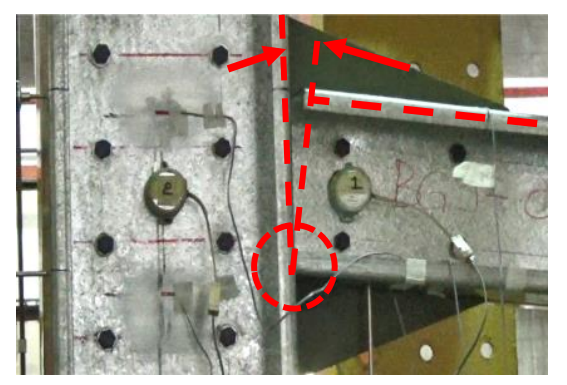

b. BGJ-08

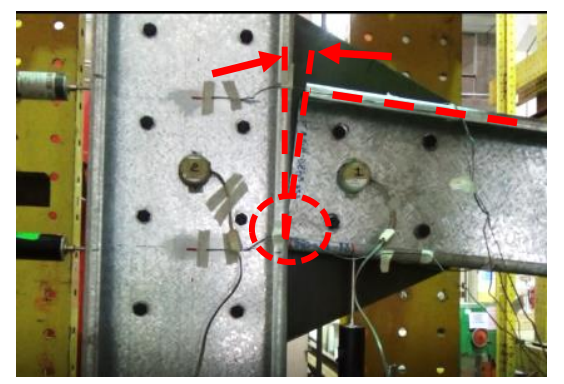

c. BGJ-09

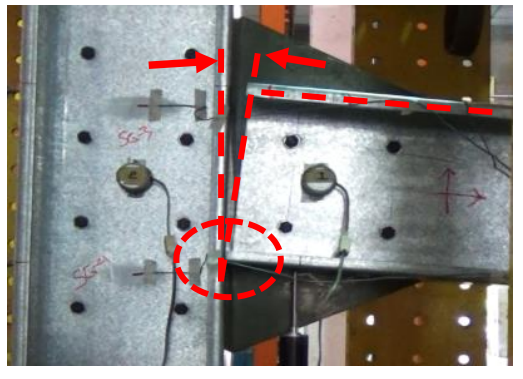

Figure 10. Connection deformation for BGJ specimens

The deformation of the joints is visibly dominated by the column flange in bending for IJT-07, IJT-08, and IJT-09 (Figure 11). This occurs because the maximum tensile force of the bolt is in the tension zone and, at the same time, the seat angle pushes the column flange in the compression zone. The presence of high stress in the compression zone results in local buckling of the column flanges.

There is also a visible rotation of the gusset plate, which results in an excessive stress on the bolt and bolt hole. There was no buckling mode or bending failure on the gusset plate, flange cleat, web cleat and the bolts. Therefore, the joint deformation could be due to a bearing failure of the CFS. The deformation shape was an indication that the thickness of the CFS plays a significant role in the deformation and failure mode of the proposed connection.

a. IJT-07

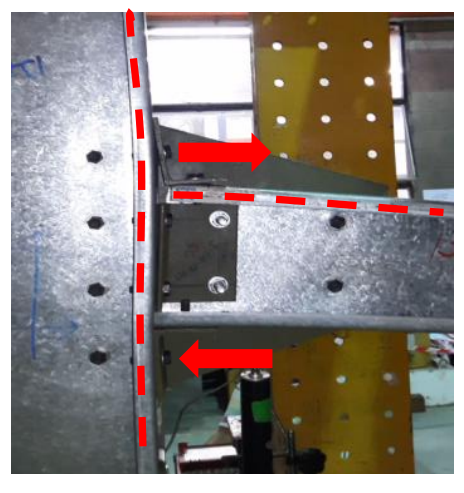

b. IJT-08

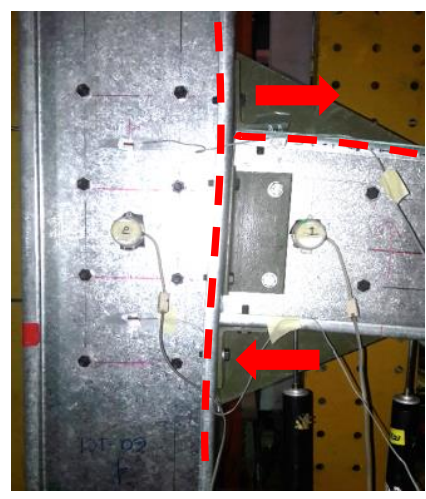

c. IJT-09

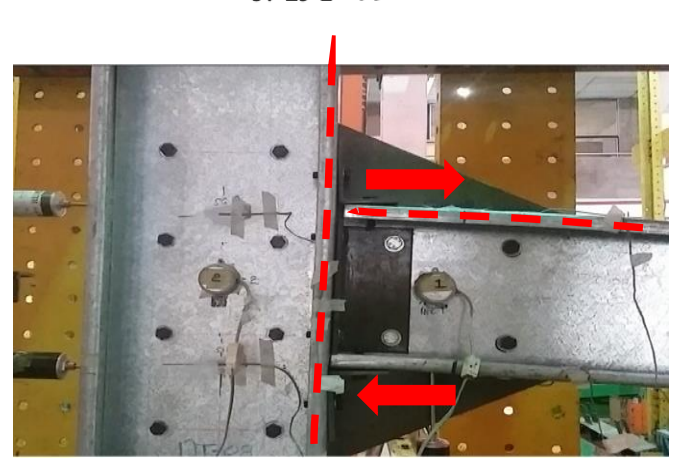

Figure 11. Connection deformation for IJT specimens

\section{Moment-Rotation Curve}

The moment-rotation curve of the specimens was plotted in order to understand the behavior of the connection, where the stiffness, rotation capacity, and maximum moment resistance can be established. Figure 12(a) displays the moment-rotation curve plotted for BGJ-07, BGJ-08, and BGJ-09. The test results show that the increase in the beam depth enhanced the moment resistance 
and the stiffness of the connection. Referring to Figure 12(b), the gusset plate connection of the test specimen can be categorized as ductile, as the rotation at the ultimate load was more than 0.03 rad. The joints can be categorized as partial strength as the moment resistance exceeded $25 \%$ of the beam bending moment $\left(0.25 \mathrm{M}_{\mathrm{cx}}\right)$ but was lower than $\mathrm{M}_{\mathrm{cx}}$.

(a) M- $\phi$ curves

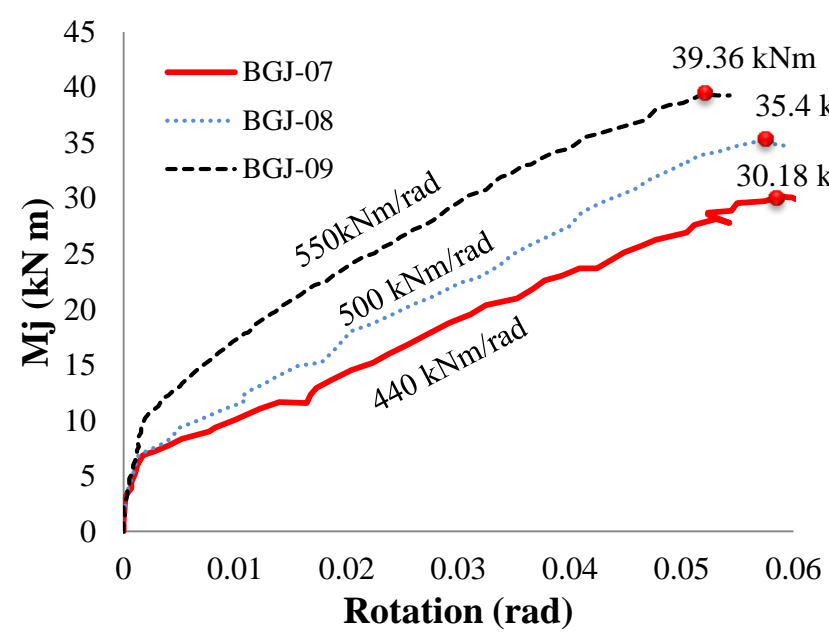

(b) M/Mcx curves

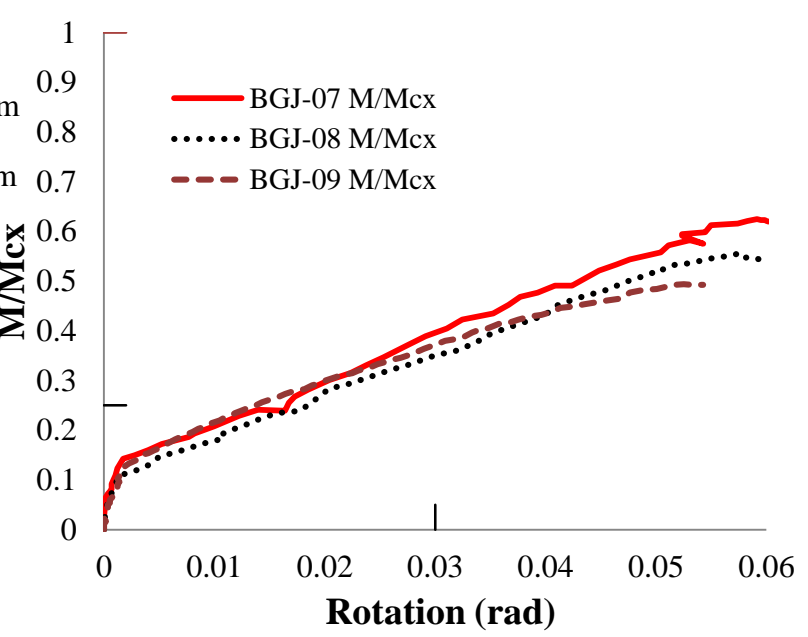

Figure 12. M- $\phi$ and M/Mcx curves for BGJ specimens (gusset plate only)

Figure 13 displays the experimental results for IJT-07, IJT-08, and IJT-09. The connection stiffness information for IJT-07 was recorded as $S_{j}=640$ and a maximum moment resistance of $37 \mathrm{kNm}$. The connection capacity for the IJT-08 specimen was $\mathrm{M}_{\mathrm{j}}=43 \mathrm{kNm}, \mathrm{S}_{\mathrm{j}}$ $=960 \mathrm{kNm} / \mathrm{rad}$ and for IJT-09 $\mathrm{M}_{\mathrm{j}}=50 \mathrm{kNm}$ and $\mathrm{S}_{\mathrm{j}}=1020 \mathrm{kNm} / \mathrm{rad}$ (Figure 13(a)). With the same procedures as above, the specimens are categorized as ductile because of the rotation by more than $0.03 \mathrm{rad}$ and the partial strength (Figure 13(b)). Table 4 shows a summary of the experimental results, and it can be concluded that all the connections can be categorized as ductile and partial strength. The difference between the ultimate rotations between all specimens was not that significant. The influence of the beam dimensions is presented in Table 5 , expressed by the moment and stiffness ratio to the specimen with the maximum beam dimensions (BGJ-09 and IJT-09 as benchmarks). Overall, the ratio shows an increase in moment resistance and joint stiffness. For example, BGJ-09 $\left(\mathrm{M}_{\mathrm{j}}=39.36 \mathrm{kNm}, \mathrm{S}_{\mathrm{j}}=550\right.$ $\mathrm{kNm} / \mathrm{rad})$ has higher values than BGJ-07 $\left(\mathrm{M}_{\mathrm{j}}=30.18 \mathrm{kNm}, \mathrm{S}_{\mathrm{j}}=440 \mathrm{kNm} / \mathrm{rad}\right)$, the moment ratio was $R M_{j}=1.30$ (from 39.36/30.18), and the stiffness ratio was $R_{j}=1.25$ (from 550/440). Table 6 displays the effect of the connection types on the connection performance, expressed by the ratio of the experimental results of IJT to those of BGJ. As an illustration, IJT-07 $\left(\mathrm{M}_{\mathrm{j}}=\right.$ $\left.37 \mathrm{kNm}, \mathrm{S}_{\mathrm{j}}=650 \mathrm{kNm} / \mathrm{rad}\right)$ was higher than BGJ-07 $\left(\mathrm{M}_{\mathrm{j}}=30.18 \mathrm{kNm}, \mathrm{S}_{\mathrm{j}}=440 \mathrm{kNm} / \mathrm{rad}\right)$, so the moment ratio was $\mathrm{RM}_{\mathrm{j}}=1.23$ (from 37/30.18) and the stiffness ratio was $\mathrm{RS}_{\mathrm{j}}=1.48$ (from 650/440). The results proved that the use of the top, seat and web angles could improve the performance of the connection, especially in stiffness, which was almost 1.4 times higher. 

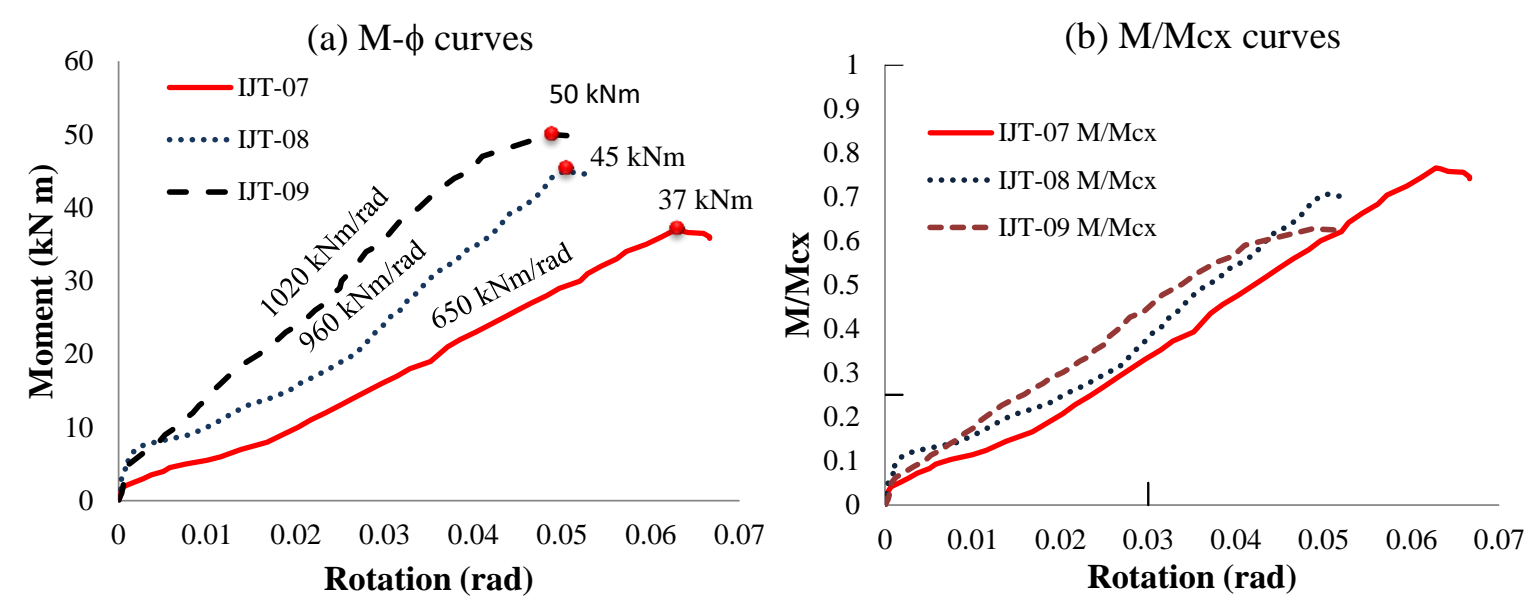

Figure 13. M- $\phi$ and M/Mcx curves for IJT specimens (gusset plate, top, seat and web angles)

Table 4. Experimental Results

\begin{tabular}{ccccc}
\hline Sample & $\begin{array}{c}\mathbf{M}_{\mathbf{j}, \text { Exp }} \\
\mathbf{k N m}\end{array}$ & $\begin{array}{c}\mathbf{S}_{\mathbf{j}, \text { Exp }} \\
\mathbf{k N m} / \mathbf{r a d}\end{array}$ & $\begin{array}{c}\boldsymbol{\phi}_{\mathbf{j}, \text { Exp }} \\
\mathbf{r a d}\end{array}$ & Connection Classification \\
\hline BGJ-07 & 30.18 & 440.00 & 0.059 & Partial strength, ductile \\
BGJ-08 & 35.40 & 500.00 & 0.058 & Partial strength, ductile \\
BGJ-09 & 39.36 & 550.00 & 0.053 & Partial strength, ductile \\
IJT-07 & 37.00 & 650.00 & 0.063 & Partial strength, ductile \\
IJT-08 & 45.00 & 960.00 & 0.050 & Partial strength, ductile \\
IJT-09 & 50.00 & 1020.00 & 0.049 & Partial strength, ductile \\
\hline
\end{tabular}

Table 5. Effect of Beam Size

\begin{tabular}{cccc}
\hline Sample A & Sample B & $\mathbf{R M}_{\mathbf{j}}$ & $\mathbf{R S}_{\mathbf{j}}$ \\
\hline BGJ-09 & BGJ-07 & 1.30 & 1.25 \\
BGJ-09 & BGJ-08 & 1.11 & 1.10 \\
\hline Average & & 1.21 & 1.18 \\
\hline IJT-09 & IJT-07 & 1.35 & 1.57 \\
IJT-09 & IJT-08 & 1.11 & 1.06 \\
\hline Average & & 1.23 & 1.32 \\
\hline
\end{tabular}

Table 6. Ratio between IJT and BGJ

\begin{tabular}{cccc}
\hline IJT & BGJ & $\mathbf{R M}_{\mathbf{j}}$ & $\mathbf{R S}_{\mathbf{j}}$ \\
\hline IJT-07 & BGJ-07 & 1.23 & 1.48 \\
IJT-08 & BGJ-08 & 1.27 & 1.92 \\
IJT-09 & BGJ-09 & 1.27 & 1.85 \\
\hline
\end{tabular}

\section{Moment-Rotation Experimental Vs Analytical Results}

One of the easiest ways to compare the analytical and experimental results is by presenting all the curves, as shown in Figure 14(a), Figure 14(b) and Table 7. The experimental results show higher values than the analytical ones for all specimens. The ratio of experimental to analytical values was between 1.31 and 1.5 for moment resistance and 1.07 and 1.37 for stiffness. The maximum ratio of the moment resistance $\left(\mathrm{M}_{\mathrm{j}, \mathrm{Exp}} / \mathrm{M}_{\mathrm{j}, \mathrm{Ec} 3}\right)$ was indicated in specimen BGJ-09 (1.5), and the maximum ratio of the stiffness $\left(\mathrm{S}_{\mathrm{j}, \mathrm{Exp}} / \mathrm{S}_{\mathrm{j}, \mathrm{Ec} 3}\right)$ was identified in BGJ-07 (1.37). The results, however, are quite conservative for the predicted values. 
Table 7. Experimental and Parametric Results

\begin{tabular}{|c|c|c|c|c|c|c|}
\hline Sample & $\begin{array}{l}\mathbf{M}_{\mathrm{j}, \mathrm{Exp}} \\
\mathbf{k N m}\end{array}$ & $\begin{array}{c}\mathbf{M}_{\mathbf{j}, \mathrm{EC} 3} \\
\mathbf{k N m}\end{array}$ & $\begin{array}{c}S_{\mathrm{j}, \operatorname{Exp}} \\
\mathbf{k N m} / \mathbf{r a d}\end{array}$ & $\begin{array}{c}\mathbf{S}_{\mathrm{j}, \mathrm{EC} 3} \\
\mathbf{k N m} / \mathbf{r a d} \\
\end{array}$ & $\begin{array}{c}\mathbf{M}_{\mathbf{j}, \operatorname{Exp}} / \\
\mathbf{M}_{\mathbf{j}, \mathrm{EC} 3} \\
\end{array}$ & $\begin{array}{l}\mathbf{S}_{\mathrm{j}, \mathrm{Exp}} / \\
\mathbf{S}_{\mathrm{j}, \mathrm{EC} 3} \\
\end{array}$ \\
\hline BGJ-07 & 30.18 & 22.33 & 440 & 320.75 & 1.35 & 1.37 \\
\hline BGJ-08 & 35.40 & 26.23 & 500 & 467.48 & 1.35 & 1.07 \\
\hline BGJ-09 & 39.36 & 26.23 & 550 & 469.10 & 1.50 & 1.17 \\
\hline IJT-07 & 37.00 & 28.35 & 650 & 506.48 & 1.31 & 1.28 \\
\hline IJT-08 & 45.00 & 33.74 & 960 & 758.77 & 1.33 & 1.27 \\
\hline IJT-09 & 50.00 & 35.58 & 1020 & 861.77 & 1.41 & 1.18 \\
\hline
\end{tabular}

a. BGJ specimen

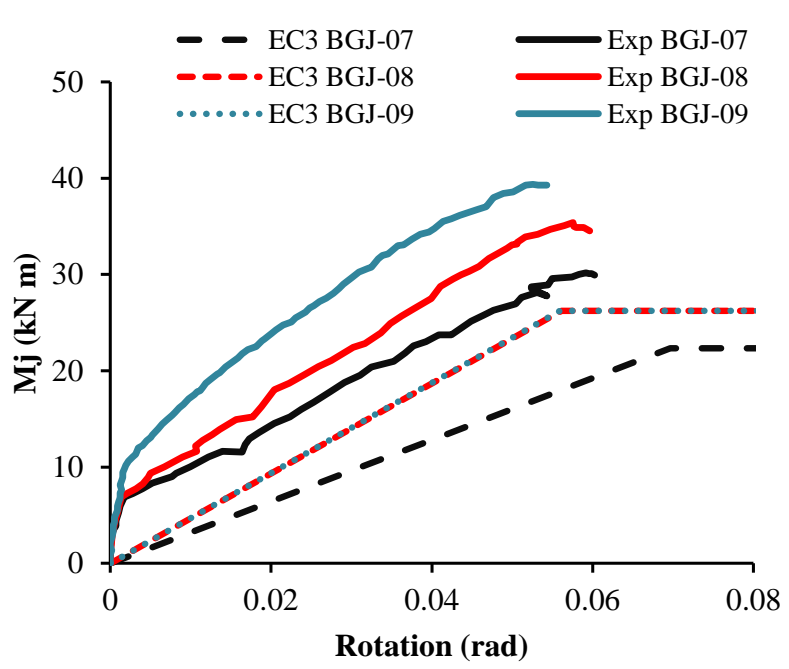

b. IJT specimen

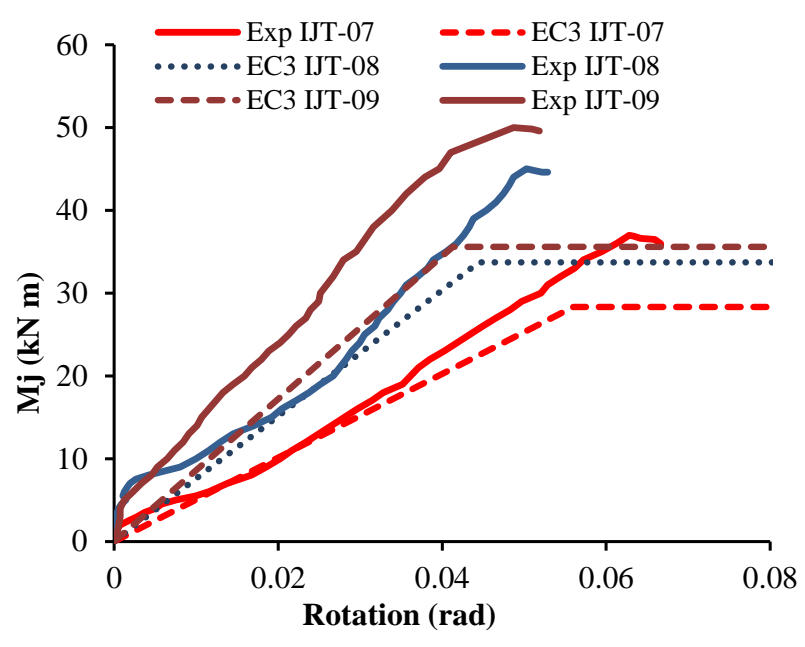

Figure 14. M- $\phi$ experimental and prediction curves

\section{Conclusions}

The experimental results demonstrating the actual behavior for both types of proposed connections (with the gusset plate only and with the gusset plate plus top, seat and web angles) are presented in this paper. The results from the experimental tests are compared with the predicted values based on EC3. The proposed connections for CFS presented in this paper can be concluded as follows:

- The failure mode for BGJ specimens was dominated by rotations of the gusset plates and beams. Local buckling occurred due to the bottom beam flange exerting compression force on the column flange in the compression zone.

- For IJT specimens, flexural deformation was detected in the column flange due to the presence of bolts at the tension zone. Rotation also developed in the gusset plates and beams but was limited by the top, seat and web angles. Buckling mode in the column flange was also detected at the final load,

- BGJ specimens showed more ductile connections than IJT specimens. The addition of the top, seat and web angles reduced the connection's ductility, but not very significantly. 
- From the experimental results, increasing the beam dimensions could improve the moment resistance and joint stiffness. For BGJ the average increase in performance for moment resistance is 1.21, and for the stiffness is 1.18. The IJT specimens showed a better performance, with ratios of 1.23 and 1.32 for moment resistance and stiffness, respectively. This could be due to the increased depth of the beam and bolt lever arm.

- The use of the top, seat and web angle contributed to a higher moment resistance and stiffness of connection, by more than 1.2 and 1.4. Therefore, the addition of an angle cleat can be recommended to improve the connection.

- The analytical formula was developed from previous research to estimate the stiffness of a haunched gusset plate. The prediction results were compared with the experiments and showed that the results were higher than those of the analytic formula.

\section{Acknowledgement}

Heartfelt thanks are due for the assistance given by the Structure and Construction Laboratory, Engineering Faculty, Universitas Sriwijaya, and Universiti Teknologi Malaysia Construction Research Centre (UTM-CRC) with grant number 4B235.

\section{References}

[1] D. Dubina, V. Ungureanu, and R. Landolfo, Design of Cold-formed Steel Structures: Eurocode 3: Design of Steel Structures, Part 1-3: Design of Cold-formed Steel Structures, Wiley Online Library, 2012.

[2] Y. Lee, C. Tan, S. Mohammad, J. Lim, and R. Johnston, "Numerical study of joint behaviour for top-seat flange cleat connection in cold-formed steel structures," Scientia Iranica Transactions B: Mechanical Engineering, Vol. 22, No. 4, pp. 1554-1566, 2015.

[3] T. C. Siang, Behaviour of Pin and Partial Strength Beam-to-column Connections with Double Channel Cold-formed Steel Sections, Thesis (PhD), Universiti Teknologi Malaysia, 2009.

[4] Ž. Bučmys, and A. Daniūnas, "Analytical and experimental investigation of cold-formed steel beam-to-column bolted gusset-plate joints," Journal of Civil Engineering and Management, Vol. 21, No. 8, pp. 1061-1069, 2015. doi:10.3846/13923730.2015.1084039.

[5] D. Dubina, A. Stratan, and Z. Nagy, "Full-scale tests on cold-formed steel pitched-roof portal frames with bolted joints," Advanced Steel Construction, Vol. 5, No. 2, pp. 175-194, 2009.

[6] B.A. Ali, S. Saad, and M. H. Osman, "Cold-formed steel frame with bolted moment connections," International Journal of Civil and Structural Engineering, Vol. 1, No. 3, pp. 534-544, 2010.

[7] A. Bagheri Sabbagh, M. Petkovski, K. Pilakoutas, and R. Mirghaderi, "Ductile momentresisting frames using cold-formed steel sections: An analytical investigation," Journal of Constructional Steel Research, Vol. 67, No. 4, pp. 634-646, 2011. doi:10.1016/j.jcsr.2010.11.016

[8] A. Bagheri Sabbagh, M. Petkovski, K. Pilakoutas, and R. Mirghaderi, "Development of coldformed steel elements for earthquake resistant moment frame buildings," Thin-Walled Structures, Vol. 53, pp. 99-108, 2012. doi:10.1016/j.tws.2012.01.004 
[9] M.A. El-Reedy, Construction Management and Design of Industrial Concrete and Steel Structures, CRC Press, 2010.

[10] S.R.S. Kumar, Design of Steel Structures II (Web Course), Indian Institute of Technology Madras, Chennai, 2009.

[11] A. Bagheri Sabbagh, M. Petkovski, K. Pilakoutas, and R. Mirghaderi, "Cyclic behaviour of bolted cold-formed steel moment connections: FE modelling including slip," Journal of Constructional Steel Research, Vol. 80, pp. 100-108, 2013. doi:10.1016/j.jcsr.2012.09.010

[12] J. Ye, S. M. Mojtabaei, I. Hajirasouliha, and K. Pilakoutas, "Efficient design of cold-formed steel bolted-moment connections for earthquake resistant frames," Thin-Walled Structures, 2019. doi:10.1016/j.tws.2018.12.015

[13] W. Chen, N. Kishi, and M. Komuto, Semi-rigid Connections Handbook, J. Ross Publishing, United States of America, 2011.

[14] C.S. Tan, M. Tahir, and M.M. Lawan, "Experimental investigation of bolted angle joints for cold formed steel with double channel sections," International Journal of Structural Analysis \& Design, Vol. 2, No. 2, pp. 14-17, 2015. doi:10.15224/978-1-63248-062-0-30

[15] J. Reinosa, A. Loureiro, R. Gutierrez, and M. Lopez, "Analytical frame approach for the rotational stiffness prediction of beam-to-column angle connections," Journal of Constructional Steel Research, Vol. 106, pp. 67-76, 2015.

[16] Z. Kong and S.-E. Kim, "Moment-rotation behavior of top-and seat-angle connections with double web angles," Journal of Constructional Steel Research, Vol. 128, pp. 428-439, 2017.

[17] C. Faella, V. Piluso, and G. Rizzano, Structural Steel Semirigid Connections: Theory, Design, and Software, CRC Press, 1999.

[18] Z. Pisarek, "Approximated method for determining moment resistance and stiffness of bolted beam to column joints made with angle web and flange cleats," Czasopismo Inżynierii Ladowej, Środowiska i Architektury, 2018.

[19] British Standards Institution, Metallic Materials Tensile Testing (Standard No. BS EN 10002-1:2001), United Kingdom, 2001.

[20] British Standards Institution, Execution of Steel Structures and Aluminium Structures (Standard No. BS EN 1090-2:2008), United Kingdom, 2008.

[21] M.M. Lawan, Structural Performance of Cold-formed Steel with Self Compacting Concrete in a Composite Beam System, Thesis (PhD), Universiti Teknologi Malaysia, 2015.

[22] British Standards Institution, Eurocode 3: Design of Steel Structures - Part 1-8: Design of Joints (Standard No. BS EN 1993-1-8:2005 ), United Kingdom, 2005. 